\title{
NATIONAL BUREAU OF STANDARDS REPORT
}

\section{EXAMINATION OF STOCK POD SECURITY CHAIN}

\section{To}

\author{
Bureau of Research and Engineering \\ U.S. Post Office Department \\ Washington, D.C.
}

\section{NBS}

U.S. DEPARTMENT OF COMMERCE

NATIONAL BUREAU OF STANDARDS 


\section{THE NATIONAL BUREAU OF STANDARDS}

The National Bureau of Standards ${ }^{1}$ provides measurement and technical information services essential to the efficiency and effectiveness of the work of the Nation's scientists and engineers. The Bureau serves also as a focal point in the Federal Government for assuring maximum application of the physical and engineering sciences to the advancement of technology in industry and commerce. To accomplish this mission, the Bureau is organized into three institutes covering broad program areas of research and services:

THE INSTITUTE FOR BASIC STANDARDS . . p provides the central basis within the United States for a complete and consistent system of physical measurements, coordinates that system with the measurement systems of other nations, and furnishes essential services leading to accurate and uniform physical measurements throughout the Nation's scientific community, industry, and commerce. This Institute comprises a series of divisions, each serving a classical subject matter area:

-Applied Mathematics-Electricity-Metrology-Mechanics-Heat-Atomic Physics-Physical Chemistry-Radiation Physics-- Laboratory Astrophysics ${ }^{2}$-Radio Standards Laboratory, ${ }^{2}$ which includes Radio Standards Physics and Radio Standards Engineering-Office of Standard Reference Data.

THE INSTITUTE FOR MATERIALS RESEARCH . . . conducts materials research and provides associated materials services including mainly reference materials and data on the properties of materials. Beyond its direct interest to the Nation's scientists and engineers, this Institute yields services which are essential to the advancement of technology in industry and commerce. This Institute is organized primarily by technical fields:

-Analytical Chemistry-Metallurgy-Reactor Radiations-Polymers-Inorganic Materials-Cryogenics ${ }^{2}-O f f i c e$ of Standard Reference Materials.

THE INSTITUTE FOR APPLIED TECHNOLOGY ... provides technical services to promote the use of available technology and to facilitate technological innovation in industry and governnient. The principal elements of this Institute are:

-Building Research-Electronic Instrumentation-Technical Analysis-Center for Computer Sciences and Technology-Textile and Apparel Technology Center-Office of Weights and Measures -Office of Engineering Standards Services-Office of Invention and Innovation-Office of Vehicle Systems Research-Clearinghouse for Federal Scientific and Technical Information ${ }^{3}$-Materials Evaluation Lahoratory--NBS/GSA Testing Laboratory.

\footnotetext{
3eadquarters and Laboratories at Gaithersburg, Maryland, unless otherwise noted; mailing address Washington, D. C.. 20234.

2 Located at Boulder, Colorado, 80302.

${ }^{3}$ Located at 5285 Port Royal Road, Springfield, Virginia 22151.
} 


\title{
NATIONAL BUREAU OF STANDARDS REPORT NBS PROJECT \\ 4213417 \\ MAY 161968 \\ NBS REPORT \\ 9829
}

\section{EXAMINATION OF STOCK POD SECURITY CHAIN}

\author{
By \\ W. F. Gerhold \\ Engineering Metallurgy Section \\ Metallurgy Division \\ To \\ Bureau of Research and Engineering \\ U.S. Post Office Department \\ Washington, D. C.
}

IMPORTANT NOTICE

NATIONAL BUREAU OF ST for use within the Government. and review. For this reason, th whole or in part, is not author Bureau of Standards, Washingte the Report has been specitically
Approved for public release by the Director of the National Institute of Standards and Technology (NIST) on October 9, 2015 ss accounting documents intended subjected to additional evaluation listing of this Report, either in 3 Office of the Director, National iy the Government agency for which opies for its own use.

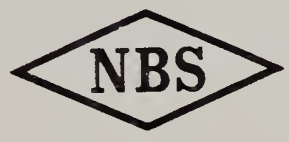

U.S. DEPARTMENT OF COMMERCE 

Reference: (a) Post Office Department, Bureau of Research and Engineering, letter dated February 15, 1968, RE-17-68(R).

Introduction: A $2 \mathrm{ft}$ (approx.) length of zinc-coated stock POD security chain was submitted under Reference (a). It was requested that an investigation be initiated to establish the reason for the low impact resistance of this type of chain.

Specific requirements for this chain are that it be in accordance with Federal Specification RR-C-27la for a Type I, Grade C, Class 4, welded steel proof coil chain. Other requirements are that it shall be zinc coated, case hardened to a depth of no less than 0.005 inch and shall be file hard. The nominal (trade) size shall be $3 / 8^{\prime \prime}$ and shall conform to the dimensions and physical requirements shown in Table VII of Federal Specification RR-C-27la.

Mechanical Properties: A one foot length of chain was loaded in tension to a proof load of 3720 pounds. The load was removed and the links were examined for indications of failure as outlined in paragraph 4.4.1.4 of Federal Specification RR-C-27la; there were no failures. The load was reapplied and increased until failure of the chain had occurred. This load (breaking load) was 8,240 pounds. The specification requirement for $3 / 8$ inch nominal (trade) size of chain is 7,440 pounds minimum. Fracture occurred at two areas on the fifth link of the ten link segment. All of the links except one contained secondary cracks at the ends of the links. There were no cracks at the weld areas on any of the links.

An additional tensile test, not required for specification purposes, was performed on a single link in order to determine the ductility of the weld. The link was cut through on the side opposite the weld. A tensile load was applied to the link and was increased until fracture occurred at a load of 2210 pounds. A sudden decrease in load was noted when the applied load reached 1700 pounds. This was believed to be the yield load or the load required to produce initial cracking. There were no failures in the weld area, but secondary cracks were observed at areas on each side of the weld approximately $1 / 4$ inch from the weld. Fracture occurred at an area approximately $1 / 2$ inch from the weld.

The fracture surfaces on all of the broken links had a granular (cleavage) appearance and there was no indication of a reduction in area at the fracture. This indicates that the links failed in a brittle manner. 

A compression (or crushing) test was performed on a single link. The link was placed on one edge between two rams and a compressive load was applied. This load was increased until fracture occurred. A sudden decrease of load at 5580 pounds indicated that cracking had initiated or that the yield load had been reached. Fracture occurred at 8,380 pounds at both ends of the link; secondary cracks and partial fractures were noted at the weld area and at the opposite edge. Examination of the areas where complete fracture was noted, revealed that they were also of a brittle nature.

Chemical Analyses: Sections were cut from two different chain links for chemical analysis of the carbon content in the core areas of the steel. The results of these analyses, based on the average of duplicate determinations, showed that the carbon content of the steel was $0.05 \%$. Federal Specification $R R-C-271$ a requires that the chemical composition of the steel be no greater than $0.35 \%$. There is no minimum requirement.

Metal lographic Examination and Hardness Tests: One link was sectioned and prepared for metallographic examination. The depth of the carburized case was found to be approximately 0.04 inch. Figure 1 shows the gradation of the carbon penetration from the outer edge, where it is at a maximum, to the core where it approaches the carbon content of the carbon steel used in the fabrication of the chain. Examination of the microstructure at a higher magnification (figure 2) revealed the following microstructural conditions:

a. Tempered martensite plates (dark needlelike structures).

b. Untempered martensite ( 1 ight gray areas).

c. Nodular pearlite (dark gray areas).

d. Cementite at the grain boundaries.

e. Large prior austenitic grain size as indicated by the size of the tempered martensite plates and the boundaries outlined by cementite.

This structure, because of conditions $b, d$, and e above, would tend to be brittle. We believe it was produced by quenching the chain directly from the carburizing temperature without a subsequent tempering treatment. The long length of time or high temperature required to carburize to a 0.04 inch depth would have produced the large austenite grains. A delay in quenching or cooling at a rate less than the critical cooling rate could produce cementite boundaries and pearlite. The darkened martensite plates indicate that the initial martensite was formed at high temperatures and was tempered during the cool down, rather than during a subsequent tempering treatment. The fact that the smaller martensitic areas appear untempered indicates that no adequate tempering treatment was applied after cool down. 
Microhardness determinations (KHN (500 gr.)) were obtained at several areas across the approximate center of the cross section. These determinations converted to approximately equivalent Rockwell hardness values revealed: (1) the hardness of the outer case area was $R_{c}$ 63-64; (2) the hardness of the intermediate zone between the outer case and the core was $R_{c} 50$ at the extreme outside to $R_{c} 33$ adjacent to the core; and ( 3 ) the hardness of the core was $R_{B} 78-79$. Specifications require only that the chain be file hard. In this respect the carburized case was resistant to abrasion by a file.

Reheating, Hardening and Tempering: Since the results obtained from the above tests and examinations showed that the carburized case was excessively brittle, an experiment was conducted to determine if additional heat treatment would improve the ductility of the case without significant decrease in hardness. Specimens were stripped of the zinc coating by immersion in a $1: 1$ hydrochloric acid solution, rinsed and dried. They were then heated to $1425^{\circ} \mathrm{F}$ for 20 minutes, quenched in water, tempered for $11 / 2$ hours at $350^{\circ} \mathrm{F}$ and air cooled.

Metal lographic examination of the case in a section cut from one of the specimens (figures 3 and 4 ) revealed that the grain had been refined considerably, with the result that all martensite present had fine plate size. There was no evidence of cementite at grain boundaries; instead it was dispersed as fine spheroids. Nor was there any trace of pearlite. All of the martensite appeared uniformly tempered. A comparison of figures 2 and 4 , both at the same magnification, strikingly reveals the improvement brought about in the structure by this heat treatment. Microhardness determinations were obtained for comparison with those obtained for the stock POD security chain. The hardness at the surface was $R_{c}$ 63-64. This is sufficiently hard to resist the abrasive action of a file.

A compression test was performed on a half link which had been given the additional heat treatment. In contrast to the behavior of the stock POD security chain, this specimen showed a significant amount of ductility as indicated by the slow decrease in load from the time cracks were initiated until complete fracture occurred. There was no evidence of a granular appearance on the fracture surface.

Conclusions: The results obtained from an examination of stock POD security chain revealed that it met the requirements as set forth in Federal Specification RR-C-27la for a Type I, Grade C, Class 4, welded steel proof coil chain and the additional requirements as specified by the Post office Department. 

However, it was determined that the stock chain was susceptible to failure due to the extreme brittleness of the carburized case. In order to improve the ductility without decreasing the hardness, it is recommended that the chain be given an additional heat treatment after carburization. This should consist of reheating to a temperature of $1425^{\circ} \mathrm{F}$, holding at this temperature for one-half hour and then quenching immediately in water. Care should be taken to prevent surface decarburization. Hardening should be followed by tempering at $350^{\circ} \mathrm{F}$ for $11 / 2$ hours.

It should also be possible to improve toughness by decreasing the thickness of the case. Since a minimum case thickness of 0.005 inch is required, it seems unnecessary to have a case thickness of 0.04 inch. It is the purpose of the case to supply sufficient hardness so as to resist cutting by a saw. The core, on the other hand is designed to support the case and provide toughness. Even though the suggested heat treatment improves the toughness of the case considerably, the core is still the principal toughness contributor and therefore reducing its area by increasing the amount of case would normally be detrimental in a situation where brittleness is a problem. A thinner case would resist sawing equally as well but for not as long. 



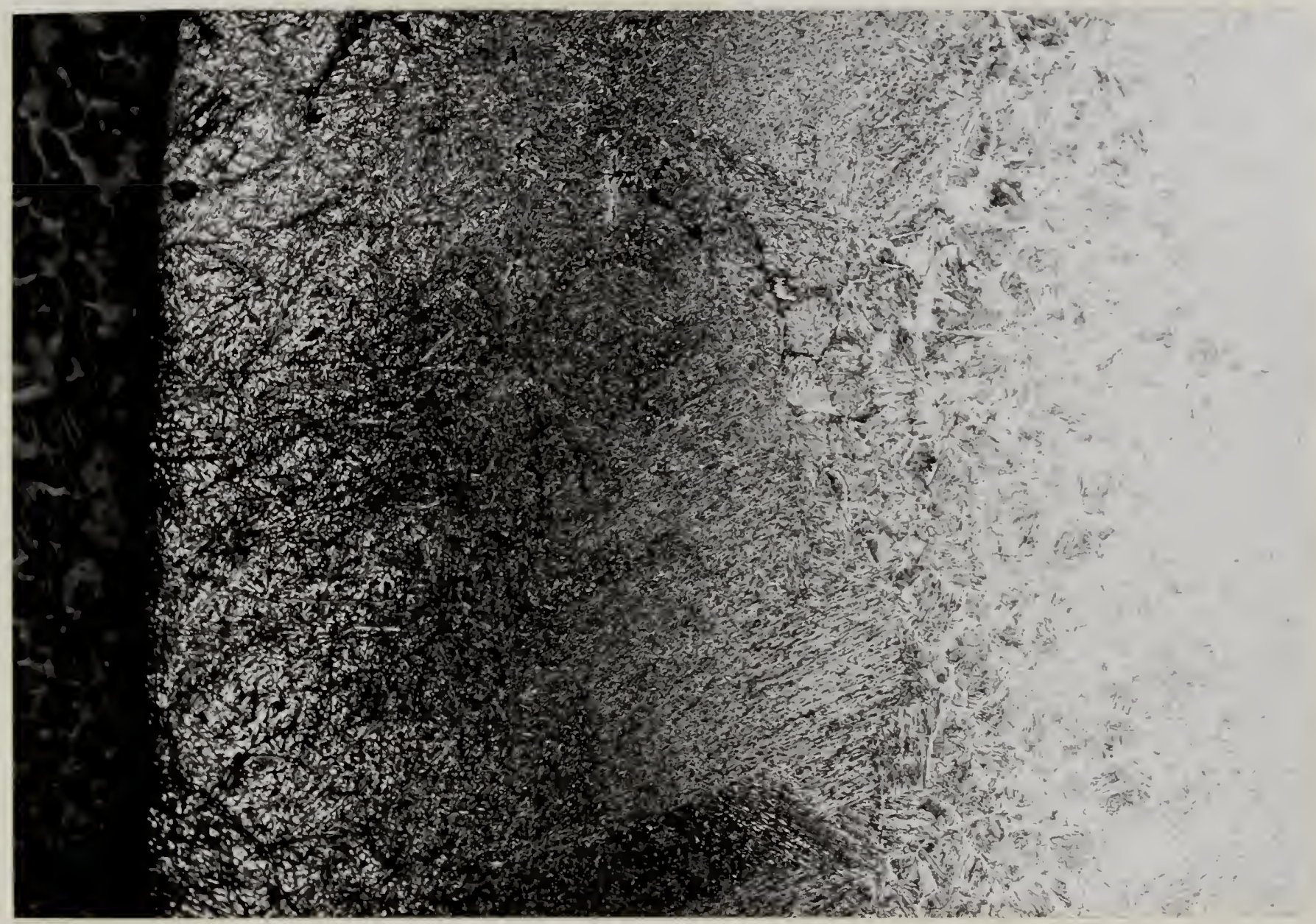

Figure 1. Microstructure of a section from a stock POD security chain link. Carburized case is approximately 0.04 inch thick. Photomicrograph shows the gradation of the carbon penetration from the outer edge (darker area) where it is at a maximum to the lighter etching core area where it is at a minimum approaching the carbon content of the core. Etched with nital. X 100 . 



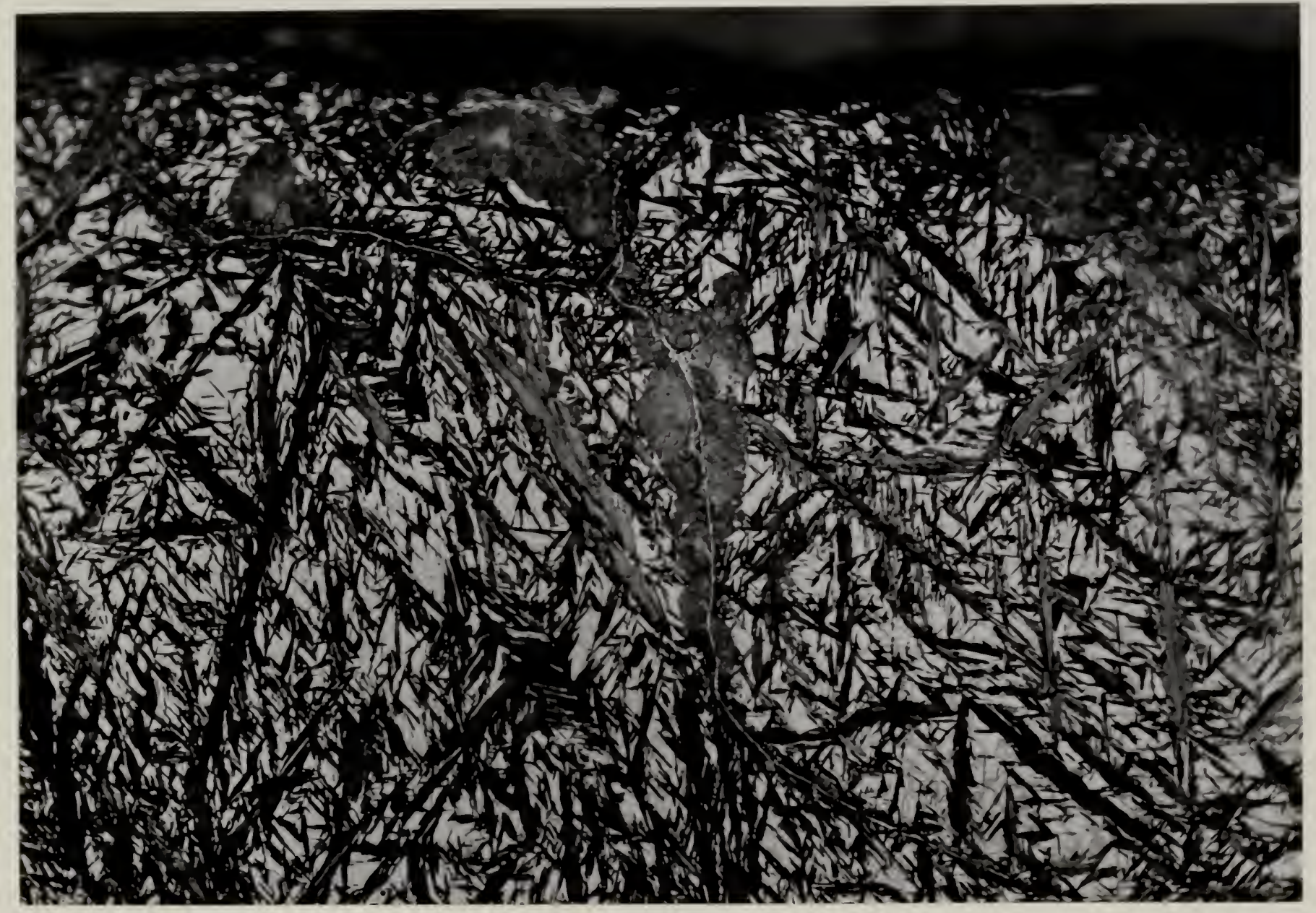

Figure 2. A portion of the area shown in Figure 1 showing the following conditions: (a) tempered martensite plates (dark needlelike structures), (b) untempered martensite (light gray areas), (c) nodular pearlite (dark gray areas), (d) cementite at the grain boundaries and (e) large prior austenitic grain size as indicated by the size of the tempered martensite plates and the boundaries outlined by cementite. Etched with nital. X 500 . 



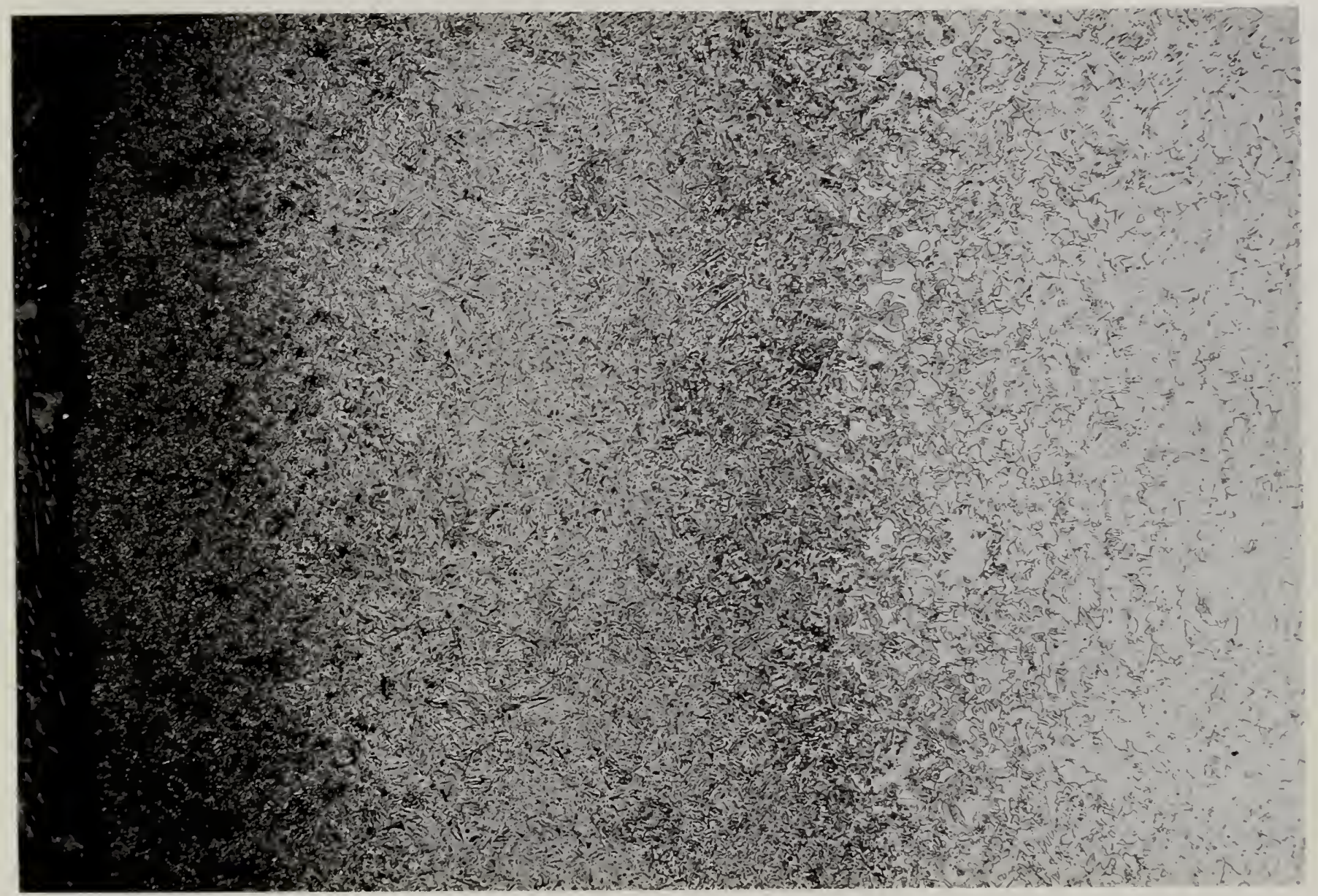

Figure 3. Microstructure of stock POD security chain after (1) reheating to $1425^{\circ} \mathrm{F}$ for 20 minutes and water quench and (2) tempering for $11 / 2$ hours at $350^{\circ} \mathrm{F}$ and air cool. Matrix of carburized case is tempered martensite with some small particles (not visible at this magnification) of $\mathrm{Fe}_{3} \mathrm{C}$. Core matrix is ferrite with some pearlite. Etched with nital. ₹ 100 . 



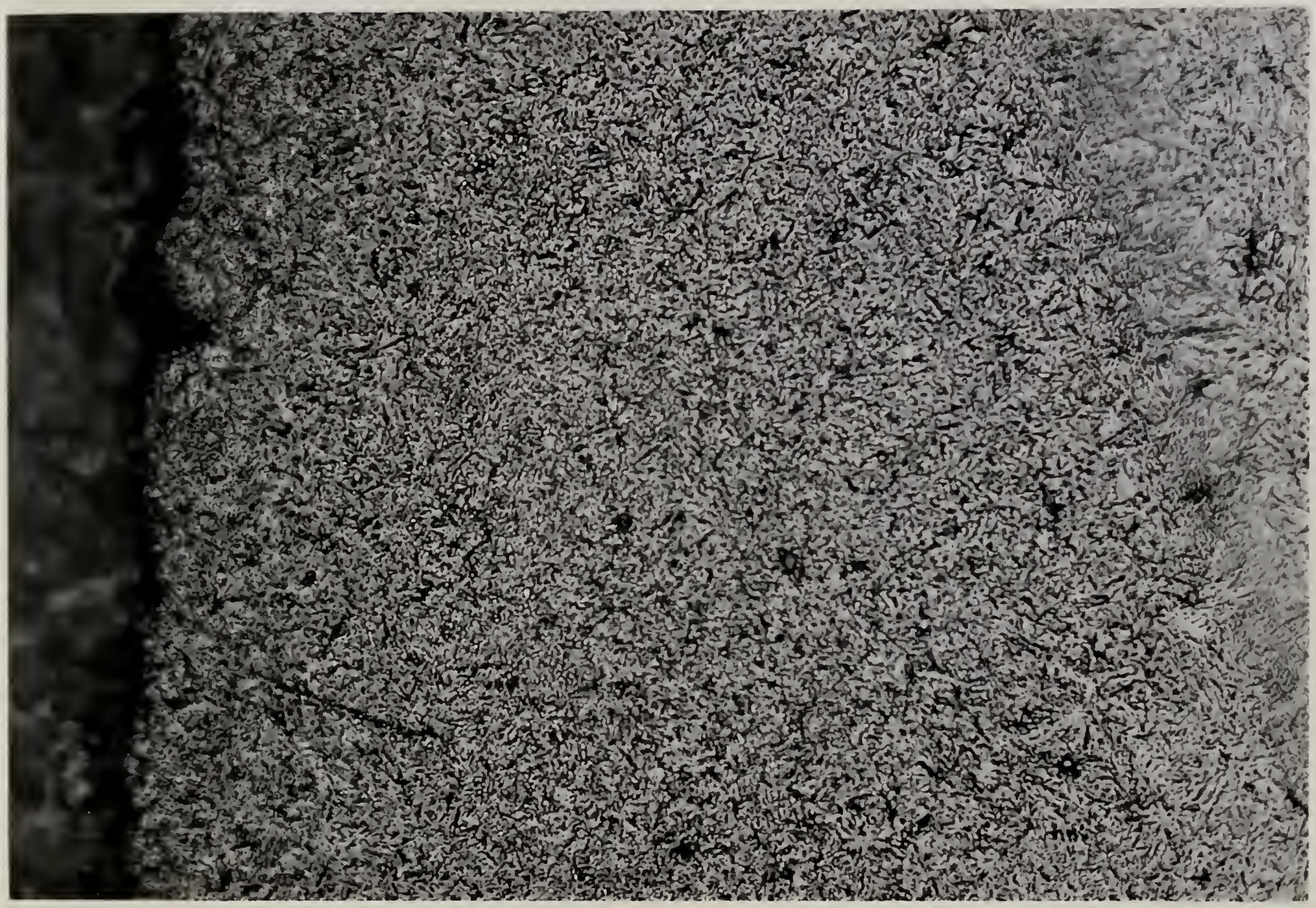

Figure 4. Portion of carburized case area of stock POD security chain after additional heat treatments noted in Figure 3. Grain size is very fine. Spherodized particles of $\mathrm{Fe}_{3} \mathrm{C}$ are scattered throughout the martensite matrix. Etched with nital. X 500 . 


